\title{
Cytotoxicity Study of High Temperature Wool (HT Wool) by Cell Magnetometric Evaluation
}

\author{
Yuichiro Kudo, Makoto Kotani and Yoshiharu Aizawa \\ Department of Preventive Medicine and Public Health, Kitasato University School of Medicine, Japan
}

\begin{abstract}
Cytotoxicity Study of High Temperature Wool (HT Wool) by Cell Magnetometric Evaluation: Yuichiro Kudo, et al. Department of Preventive Medicine and Public Health, Kitasato University School of Medicine-Objectives: We performed a cytotoxicity study by cell magnetometry, measured lactate dehydrogenase (LDH) activity by enzyme assay, detected DNA ladder formation, and performed morphological examination by electron microscopy in order to evaluate the safety of high temperature wool ( $\mathrm{HT}$ wool), an asbestos substitute, using long and short chrysotile fibers (CF) as positive controls and phosphate buffered saline (PBS) as a negative control. Methods: Alveolar macrophages were isolated from male Fisher rats. Following the addition of iron oxide particles $\left(\mathrm{Fe}_{3} \mathrm{O}_{4}\right)$ to macrophages, HT wool, long or short CF was added. Then, the remanence strength was measured for 20 min after magnetization by an external field. Percent LDH release was calculated after determining LDH activity. DNA was detected using an apoptosis detection kit. Morphological observation was performed by taking electron micrographs of macrophages in the groups treated with HT wool and long- and short-CF. Results: Rapid relaxation, an indicator of decay of cytotoxicity, was observed by cell magnetometry immediately after magnetization was ended in the groups treated with HT wool and PBS, showing that HT wool causes no harmful effect on the cytoskeleton. The CF-treated groups had higher LDH activity than the PBS- and HT wool-treated groups. No fragmentation of DNA was observed in any group. In morphological observation, cytotoxicity in macrophages was lower in the HT wool-treated groups than in the CF-treated groups. Conclusions: The results suggest that HT wool has no cytotoxicity, as evaluated by cell magnetometry, enzyme assay, DNA ladder detection
\end{abstract}

Received Sep 17, 2009; Accepted Dec 11, 2009

Published online in J-STAGE Feb 3, 2010

Correspondence to: Y. Kudo, Department of Preventive Medicine and Public Health, Kitasato University School of Medicine, 1-151, Kitasato, Sagamihara, Kanagawa 228-8555, Japan (e-mail: yuichiro@med.kitasato-u.ac.jp) and morphological examination. (J Occup Health 2010; 52: 106-114)

Key words: Cell magnetometry, Cytoskeleton, Cytotoxicity, High temperature wool (HT wool), Relaxation

It has been reported that asbestos causes pulmonary fibrosis and malignant tumors, and many in vitro and in vivo studies have shown its toxicity. Therefore, the use of asbestos has been restricted worldwide, including in Japan ${ }^{1-3)}$, and many asbestos substitutes have been developed. A variety of man-made vitreous fibers (MMVF) such as rock wool (RW) and glass wool are currently used as asbestos substitutes. Recently, a new type of RW, high-alumina, low-silica stone wool, hightemperature wool (HT wool), has been developed. Its chemical composition is characterized by a high concentration of $\mathrm{Al}_{2} \mathrm{O}_{3}$ and a low concentration of $\mathrm{SiO}_{2}$, low biopersistence, and a high melting point. These characteristics of HT wool have enabled its use to be broadened to heat insulation and other applications, and it has extensively replaced traditional types of RW. However, since HT wool has only been used for a short time, and the IARC categorizes it as unclassifiable, evaluation of its safety is urgently needed. Since most chemical substances enter the body through the airways and are processed by alveolar macrophages, evaluation of the effects on these cells should be a useful system for screening the physiological effects of chemical substances. Furthermore, alveolar macrophages, due to their phagocytic activity, are suited for the evaluation of insoluble particles such as dust, fibrous substances like asbestos and asbestos substitutes.

Cell magnetometry is an application of lung magnetometry, which was first reported by Cohen in $1973^{4}$. The principle of cell magnetometry is to induce uptake of iron oxide particles (magnetic particles) by phagocytes and to magnetize these particles by applying an external magnetic field, followed by measurement of the strength of the remanence after cessation of external 

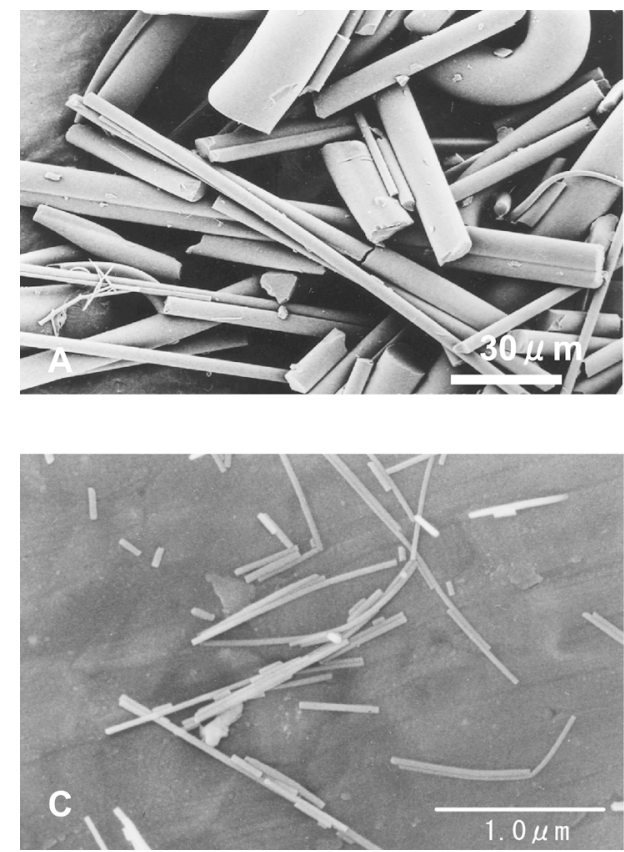

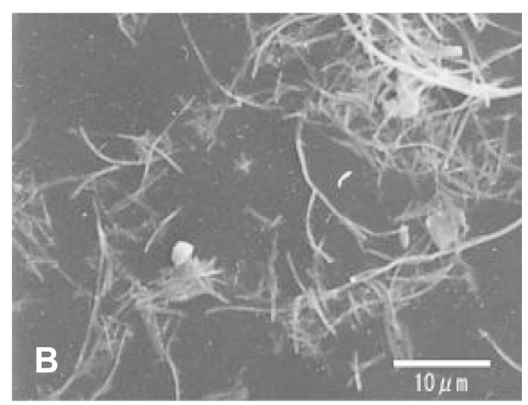

Fig. 1. A. Scanning electron micrograph of HT wool fibers. Mean length, $13.34 \pm 12.92 \mu \mathrm{m}$; mean width, $1.92 \pm 1.14 \mu \mathrm{m}$. B. Scanning electron micrograph of long CF. Mean length, $2.6 \pm$ $2.3 \mu \mathrm{m}$; mean width, $0.15 \pm 1.80 \mu \mathrm{m}$. C. Scanning electron micrograph of short CF. Mean length, $1.17 \pm 1.74 \mu \mathrm{m}$; mean width, $0.056 \pm 0.035 \mu \mathrm{m}$. magnetization, to evaluate the time course of changes in the magnetic field. The decay of the remanence after cessation of magnetization is called relaxation. During external magnetization, magnetic particles become aligned with the external magnetic field, and after its removal, these particles start to deviate from this alignment due to random rotation associated with intracytoplasmic translocation of phagocytic vesicles, and the time course of this change is called relaxation.

In the present study, the cytotoxicity of HT wool was evaluated by cell magnetometry, enzyme assay, DNA ladder detection and morphological examination by electron microscopy, using alveolar macrophages, which play a key role in the defense mechanism against foreign substances invading via the transairway route.

\section{Materials and Methods}

This experiment was performed in accordance with the Ethical Guidelines for Animal Experimentation adopted by the Institutional Review Board of Kitasato University School of Medicine (Approval No. 2004022).

\section{Materials}

Iron oxide particles, an indicator for cell magnetometry, were supplied by Toda Kogyo Co., Ltd., Japan, and HT wool, a test sample for evaluation of cytotoxicity manufactured by R Co., Ltd., Japan, was provided by the Rock Wool Association, Japan. The geometric mean diameter of the iron oxide particles was $0.26 \mu \mathrm{m}$, and the geometric mean length and width (geometric standard deviation) of HT wool were 13.34 (12.92) $\mu \mathrm{m}$ and 1.92 (1.14) $\mu \mathrm{m}$, respectively (Fig. 1A). As analyzed by fluorescent X-ray diffraction, the chemical composition of $\mathrm{HT}$ wool was approximately $43 \% \mathrm{SiO}_{2}, 18 \% \mathrm{Al}_{2} \mathrm{O}_{3}$, $16 \% \mathrm{CaO}, 10 \% \mathrm{MgO}, 6 \% \mathrm{Fe}_{2} \mathrm{O}_{3}, 2 \% \mathrm{TiO}_{2}, 2 \% \mathrm{Na}_{2} \mathrm{O}$, $1 \% \mathrm{~K}_{2} \mathrm{O}$ and $1 \% \mathrm{~S}$. As positive controls, chrysotile fibers (CF) of two different lengths (long CF supplied by Japan Fibrous Materials Research Association, and short CF supplied by the Japan Association for Working Environment Measurement) were used (Fig. 1B\&C). The fiber length and width of long CF were $2.6 \pm 2.3 \mu \mathrm{m}$ (range: $0.2-100 \mu \mathrm{m}$ ) and $0.2 \pm 1.8 \mu \mathrm{m}$ (range; $0.04-1.00$ $\mu \mathrm{m})$, respectively. Its chemical composition was approximately $46 \% \mathrm{MgO}, 46 \% \mathrm{SiO}_{2}, 3 \% \mathrm{Fe}_{2} \mathrm{O}_{3}, 2 \%$ $\mathrm{Al}_{2} \mathrm{O}_{3}$, and $1 \% \mathrm{CO}_{2}$. The fiber length and width of short $\mathrm{CF}$ was $1.2 \pm 1.7 \mu \mathrm{m}$ (mostly below $5 \mu \mathrm{m}$ ) and $0.056 \pm$ $0.035 \mu \mathrm{m}$ (range: $0.02-0.03 \mu \mathrm{m}$ ), respectively. Its chemical composition was approximately $42 \% \mathrm{MgO}$, $35 \% \mathrm{SiO}_{2}, 5 \% \mathrm{Fe}_{2} \mathrm{O}_{3}$ and $1 \% \mathrm{FeO}$.

\section{Alveolar Macrophage Preparation}

Six male Fisher rats (F344/N Slc), weighing 200-250 $\mathrm{g}$, were used. They were anesthetized with an intraperitoneal injection of sodium pentobarbital (100 mg/ $\mathrm{kg}$ ) and sacrificed by exsanguination from the abdominal aorta after making a midline abdominal incision. The lungs were collapsed by incision of the diaphragm. With the trachea exposed, a silicone tube was inserted through its opening and fixed. Alveolar lavage was carried out by infusing $4 \mathrm{~m} l$ of millipore filter filtration-sterilized $0.1 \%$ ethylenediamine tetraacetic acid in cold phosphate buffered saline (PBS), $\mathrm{pH} 7.4$, into the lungs under gentle massage of the chest, followed by recovery of the lavage fluid. This procedure was performed 10 times in total, 
and the alveolar macrophage-containing lavage fluid obtained was pooled and then subjected to centrifugation at $1,800 \mathrm{rpm}$ for $10 \mathrm{~min}$ and suspended by the addition of Macrophage-SFM liquid (Life Technologies Inc., Rockville, MD, USA) to the pellet. A portion of the suspension was used for determination of cell counts by a hemocytometer after trypan blue staining.

The alveolar macrophage suspension prepared by this procedure was diluted with Macrophage-SFM liquid so that a given amount of aliquot gave $1 \times 10^{6}$ cells per well. Each aliquot was poured into a well (Nunc Co., Roskilde, Denmark), with a cell disc of 1-cm diameter, followed by incubation at $37^{\circ} \mathrm{C}$ in $5 \% \mathrm{CO}_{2}$ for $18 \mathrm{~h}$ as follows. In cell magnetometry, enzyme assay and DNA ladder detection, iron oxide particles suspended in PBS were added at a final concentration of $50 \mu \mathrm{g} / \mathrm{m} l$ to each well, followed by the addition of HT wool fibers suspended in PBS at a final concentration of 50, 100 and $150 \mu \mathrm{g} / \mathrm{m} l$ in the experimental groups $(50,100,150 \mu \mathrm{g} /$ $\mathrm{m} l$ HT wool-treated groups). Either long or short CF was added at a final concentration of $50 \mu \mathrm{g} / \mathrm{m} l$ in the positive control groups (long or short CF-treated group), and $50 \mu l$ PBS was added in the negative control group (PBS-treated group). For electronmicroscopic observation, iron oxide particles were not added, and instead, HT wool fibers at a final concentration of 150 $\mu \mathrm{g} / \mathrm{m} l$ per well were added in the experimental groups, and either long or short CF (at a final concentration of 50 $\mu \mathrm{g} / \mathrm{m} l$ ) or $50 \mu l$ PBS was added, as positive and negative control groups, respectively.

\section{Cell Magnetometry}

Cell magnetometry was performed in the same manner as reported by Keira et al. ${ }^{5}$. After culturing alveolar macrophages for $18 \mathrm{~h}$ as described above, the glass disc harboring adherent alveolar macrophages was taken out of each well and placed in a glass weighing bottle containing $1 \mathrm{~m} l$ Macrophage-SFM liquid. The specimens were subjected to external magnetization for $1 / 100 \mathrm{~s}$ under the magnetic field of a cell magnetometer apparatus. Immediately after that, recording for $20 \mathrm{~min}$ of the remanence strength, as measured with a fluxgate-type magnetometer, was started using a pen recorder. The apparatus was operated in such a way that the sample table passed over the probe once every $6 \mathrm{~s}$. The temperature was maintained at $37^{\circ} \mathrm{C}$ by means of a hotair fan with a thermostat placed beneath the magnetic shield. The curve, which shows the level of relaxation, was obtained by measuring the remanence strength for 20 min post-magnetization. Measurement of the remanence strength for 2 min post-magnetization gave a nearly linear curve after logarithmic transformation, and the point at which this curve intersected the y-axis was designated $\mathrm{B}_{0}$. When expressing the remanence immediately after magnetization as $\mathrm{B}_{0}$ and the decay constant as $\lambda$, the remanence at time $\mathrm{t}$ (in seconds) after termination of the external magnetic field can be represented by the formula $\mathrm{B}=\mathrm{B}_{0} \mathrm{e}^{-\lambda \mathrm{t}}$, and the decay constant $(\lambda)$ was calculated based on this formula.

\section{Enzyme Assay}

After completing $18 \mathrm{~h}$ incubation, using the same method for the magnetometry, the culture media were harvested and centrifuged at 1,400 rpm for $10 \mathrm{~min}$ to collect the supernatant. Lactate dehydrogenase (LDH) activity in the supernatant was measured by the same method reported by Wroblewski et al. ${ }^{6}{ }^{6}$ using an LDHUV Test Wako (Wako Pure Chemical Industries, Ltd., Osaka, Japan) and recorded on a model U-3210 selfrecording spectrophotometer (Hitachi Ltd., Tokyo, Japan). Total LDH activity was measured in the same manner after cytolysis with the addition of $40 \%$ Triton X-100. Percent LDH release was calculated according to the following formula after determining each LDH activity released from macrophages caused by the addition of HT wool (LDH activity released) and total LDH activity: Percent $\mathrm{LDH}$ release $=\mathrm{LDH}$ activity released $\times 100 /$ total LDH activity.

\section{DNA Ladder Detection}

After completing $18 \mathrm{~h}$ incubation, using the same method for the magnetometry, DNA was extracted from the alveolar macrophages using an apoptosis ladder detection kit (Wako). The specimen thus prepared was subjected to DNA agarose gel electrophoresis. The agarose gel was prepared to contain agarose at a concentration of $1.5 \%$. The DNA specimen $(12 \mu l)$ and DNA molecular weight marker (500 bp marker: Wako) were loaded in a well with agarose gel, followed by electrophoresis at $100 \mathrm{~V}$ in Mupid-3 (Cosmo Bio Co., Ltd., Tokyo, Japan). After completion of electrophoresis, DNA was stained with ethidium bromide, followed by photography through a filter (254 nm) of a transilluminator (NLMS-20E type).

\section{Morphological Observation}

Scanning electron microscope observation was performed following culture of cells for $18 \mathrm{~h}$, as described above. Macrophages adsorbed onto the polycationicstreated glass were washed with $0.1 \mathrm{M}$ cacodylate buffer ( $\mathrm{pH}$ 7.4). Then, following prefixation with $1 \%$ glutaraldehyde at $4^{\circ} \mathrm{C}$ for $3 \mathrm{~h}$ and washing, cells were fixed with osmium tetroxide at $4^{\circ} \mathrm{C}$ for $3 \mathrm{~h}$ and washed with cacodylate buffer. For transmission electron microscopic observation, specimens thus processed were further subjected to staining, dehydration, resin treatment, embedding, ultrathin slicing with an ultramicrotome, and electron staining, followed by evaluation with a model H-600 (Hitachi). For scanning electron microscope observation, specimens were subjected to conductive 


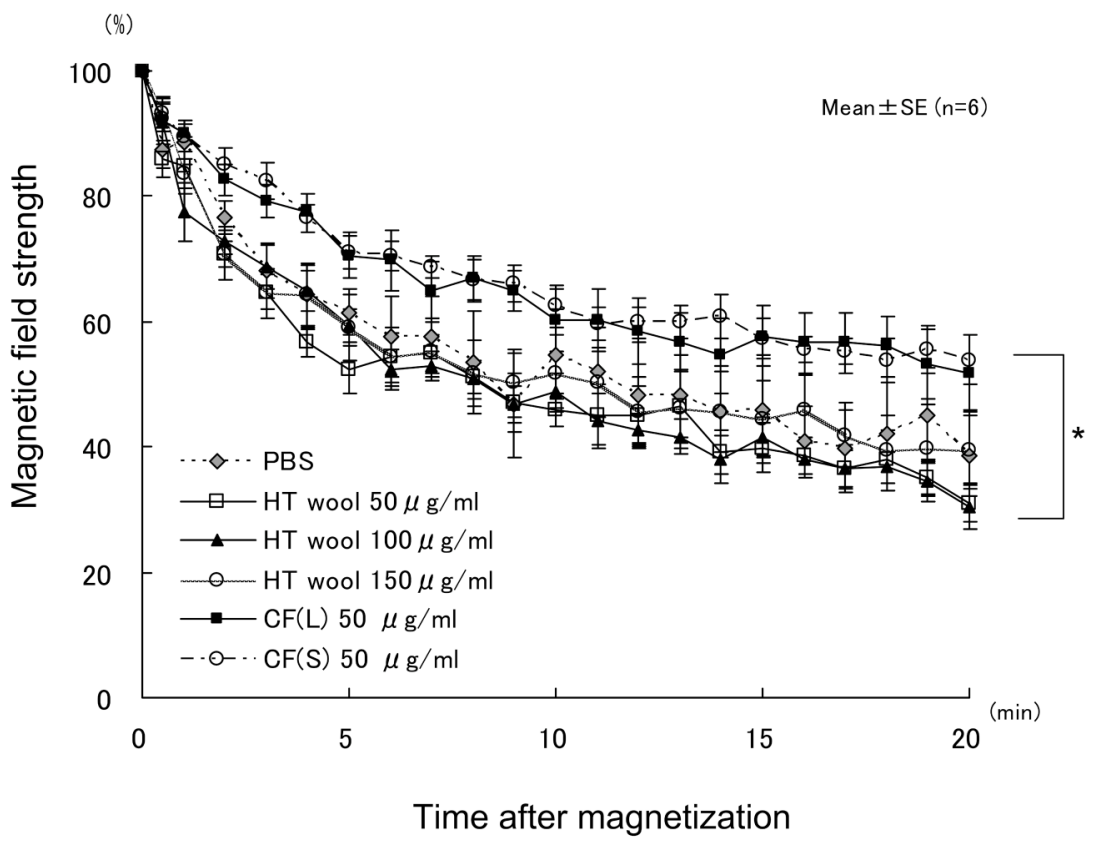

Fig. 2. Relaxation curve. There was a statistically significant difference between the 50 and $100 \mu \mathrm{g} / \mathrm{ml}$ HT wool-treated groups and short CF-treated groups $(*: p<0.05)$.

staining, dehydration, drying, and conductive treatment, followed by evaluation with a model S-4500 FE type (Hitachi).

\section{Statistical Analysis}

The results are shown as mean \pm standard error of measurements obtained for 6 rats in both the control and experimental groups. All data were analyzed by one-way analysis of variance by Stat View 5.0, and statistical analysis with multiple comparisons was performed by Scheffe's test.

\section{Results}

\section{Cell Magnetometry}

Relaxation curves were constructed by plotting values of the remanence for 20 min post-magnetization (Fig. 2). The remanence strength showed rapid relaxation: 38.55 $\pm 6.40 \%$ in the PBS-treated group and $30.95 \pm 2.85,30.55$ \pm 3.60 , and $39.41 \pm 6.10 \%$ in the 50,100 and $150 \mu \mathrm{g} / \mathrm{m} l$ HT wool-treated groups, respectively. In the CF-treated groups, however, relaxation was delayed as compared with that in the PBS- and HT wool-treated groups, as shown by values of $51.80 \pm 6.01$ and $53.90 \pm 3.88 \%$ in the long and short CF-treated groups, respectively (Fig. 2). Results of multiple comparisons by Scheffe's test showed no significant difference between the PBS- and HT wool-treated groups, whereas differences between the HT wool-treated and the long and short CF-treated groups were statistically significant $(p<0.05)$ (Fig. 2). At 2 min postmagnetization, the decay constant values were smaller in the long and short CF-treated groups than in the PBSand HT wool-treated groups: $3.25 \pm 0.34\left(\times 10^{-3} / \mathrm{s}\right)$ in the PBS-treated group, $3.06 \pm 0.29\left(\times 10^{-3} / \mathrm{s}\right), 2.97 \pm 0.26$ $\left(\times 10^{-3} / \mathrm{s}\right)$ and $2.93 \pm 0.42\left(\times 10^{-3} / \mathrm{s}\right)$ in the 50,100 and 150 $\mu \mathrm{g} / \mathrm{m} l$ HT wool-treated groups, respectively, versus 1.80 $\pm 0.30\left(\times 10^{-3} / \mathrm{s}\right)$ and $1.54 \pm 0.29\left(\times 10^{-3} / \mathrm{s}\right)$, respectively, in the long and short CF-treated groups. Multiple comparisons by Scheffe's test showed no statistical significance in the difference between the PBS- and HT wool-treated groups. However, the differences between the HT wool-treated and both the long and short CFtreated groups were statistically significant $(p<0.05)$ (Fig. 3).

\section{Enzyme Assay}

The percent release of LDH activity was $18.00 \pm 2.88 \%$ in the PBS-treated group and $21.82 \pm 6.15,23.45 \pm 4.73$, and $23.24 \pm 7.85 \%$ in the 50,100 and $150 \mu \mathrm{g} / \mathrm{m} l \mathrm{HT}$ wool-treated groups, respectively, and $33.68 \pm 7.57$ and $34.19 \pm 4.32 \%$ in the long and short CF-treated groups, respectively. Multiple comparisons by Scheffe's test demonstrated statistically significant differences between the HT wool-treated and the long and short CF-treated groups $(p<0.05)$, with no significant difference between the PBS- and HT wool-treated groups (Fig. 4). 


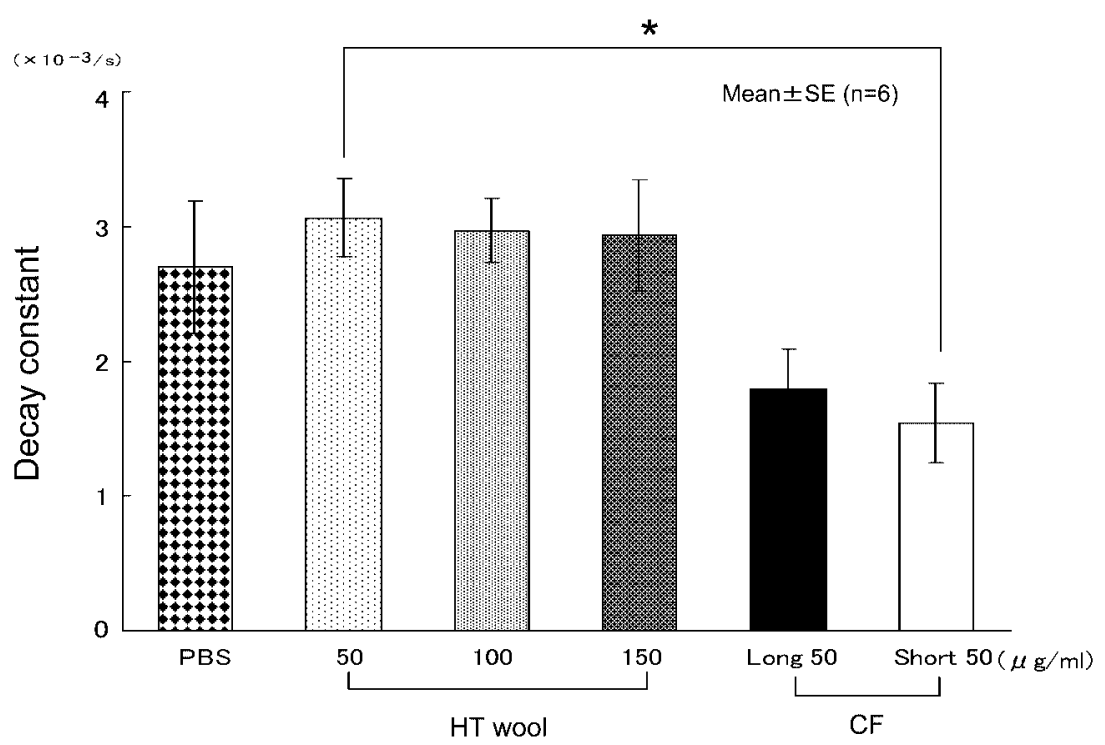

Fig. 3. Decay constant 2 min postmagnetization. There was a statistically significant difference between the $50 \mu \mathrm{g} / \mathrm{m} l \mathrm{HT}$ wool-treated groups and short CF-treated groups $(*: p<0.05)$.

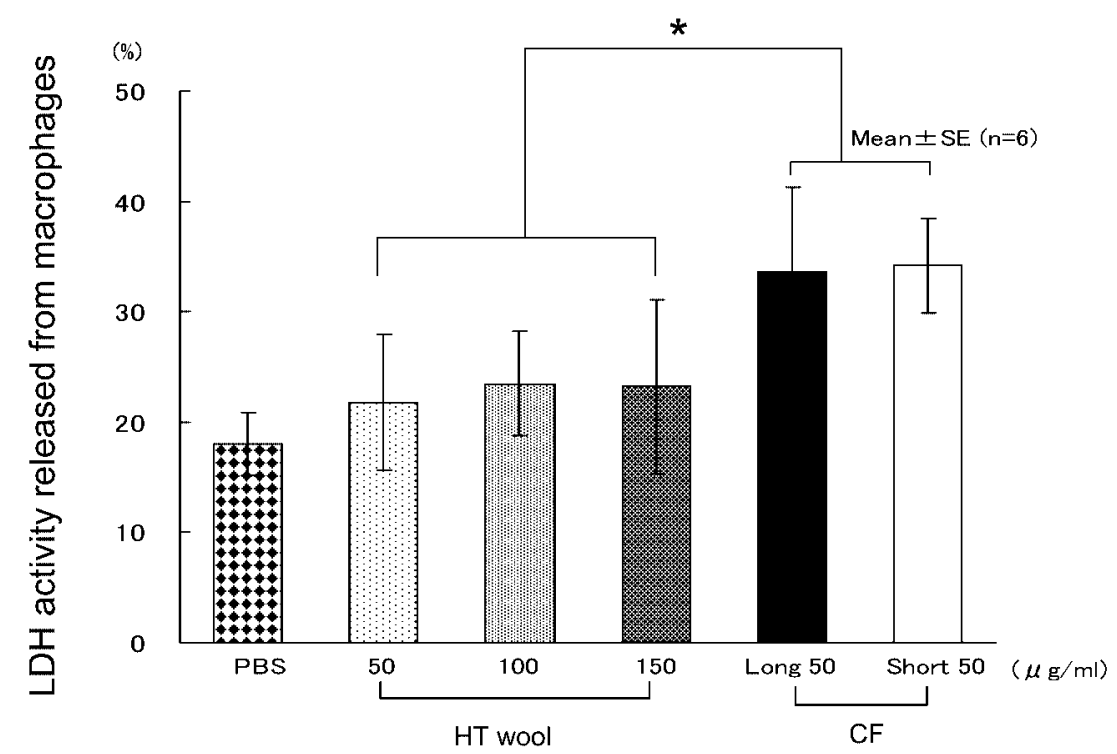

Fig. 4. Percent LDH release from alveolar macrophages. There was a statistically significant difference between the HT wool- and long and short CF-treated groups $(*: p<0.05)$.

\section{DNA Ladder Detection}

No fragmentation of DNA was observed in the PBS-, HT wool- and CF-treated groups (data not shown).

\section{Morphological Observation}

Morphological observation was carried out using a scanning electron microscope. In the PBS-treated groups, macrophages were round and the cell surface was entirely covered with numerous microvilli projecting in all directions (data not shown). In the $150 \mu \mathrm{g} / \mathrm{ml} \mathrm{HT}$ wooltreated group, some cells were stretched in the direction of the fibers, while others adhered around the fibers due to the large fiber width, with fibers penetrating through the middle of cells (Fig. 5). With the addition of $50 \mu \mathrm{g} / \mathrm{m} l$ long $\mathrm{CF}$, on the other hand, fibers were seen protruding out of the cell surface, and macrophages with a stretched 

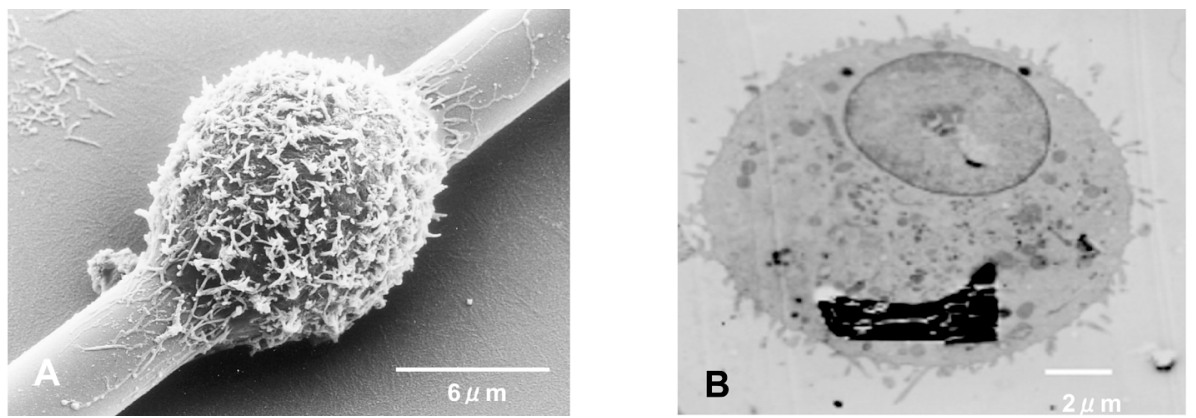

Fig. 5. (A) Electron micrograph of macrophages in the HT wool-treated group (SEM). The width of HT wool fibers is large, resulting in incomplete phagocytosis by macrophages. (B) Electron micrograph of macrophages in the HT wool-treated group (TEM). Cross-section of a HT wool fiber is seen in the macrophage cytoplasm, but no apparent degeneration of the cytoplasm is seen.
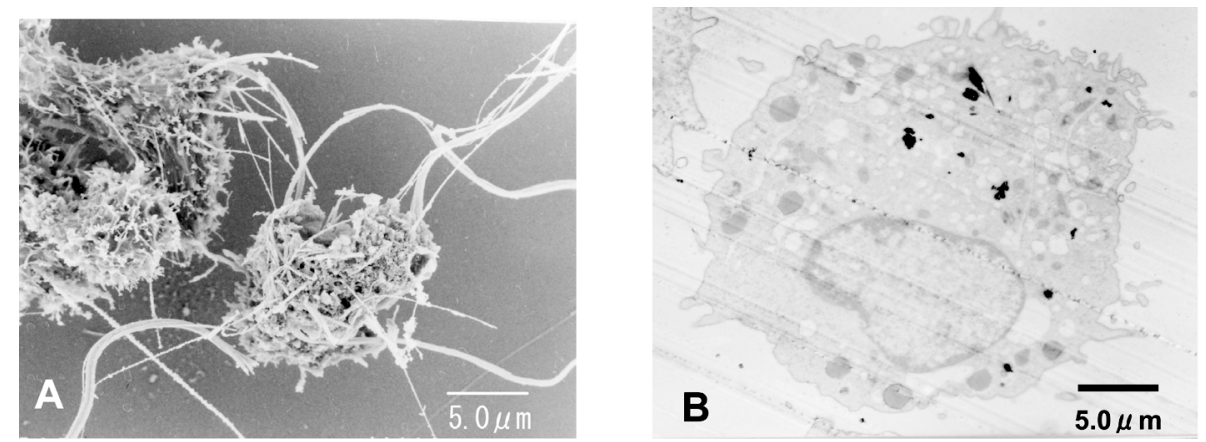

Fig. 6. (A) Electron micrograph of macrophages in the long CF-treated group (SEM). Fibers are seen protruding from the cell surface, and macrophages appear to adhere to fibers with scarce presence of microvilli. (B) Electron micrograph of macrophages in the long CF-treated group (TEM). Microvilli on the cell surface are smoothed, with vacuole formation in the cytoplasm.

cell membrane appeared to adhere to the fibers. Large numbers of fragmented $\mathrm{CF}$ were seen on the surfaces of macrophages (Fig. 6). With the addition of $50 \mu \mathrm{g} / \mathrm{m} l$ short CF, thin, short fibers clung to the macrophages (Fig. 7).

Transmission electron microscopy demonstrated phagocytic vacuoles, surrounded by a clear membrane structure, in the cytoplasm beneath the microvilli in macrophages in PBS. The nuclei were relatively large with irregular shapes, and smooth-shaped endoplasmic reticulum and lysosomes were seen in the cytoplasm. With the addition of $150 \mu \mathrm{g} / \mathrm{ml} \mathrm{HT}$ wool, cross sections of HT wool were seen in the cell walls of macrophages. However, no apparent degeneration of the cytoplasm was observed (Fig.5). On the other hand, projections on the cell surfaces were smoothed in the $50 \mu \mathrm{g} / \mathrm{m} l$ long CFtreated groups. Chrysotile fibers were broken into small pieces and taken into phagocytic vacuoles, forming vacuoles in the cells. Vacuolization was more evident in the cells that had taken up a large volume of CF. Cells with a condensed nucleus were rarely observed (Fig. 6). Vacuolization of the cytoplasm was more evident with addition of $50 \mu \mathrm{g} / \mathrm{m} l$ short CF than with $50 \mu \mathrm{g} / \mathrm{m} l$ long CF. In addition, there was an increase in the number of cells with condensed nuclei, and the most severe damage to macrophages was caused by the addition of short $\mathrm{CF}$ (Fig. 7).

\section{Discussion}

We evaluated HT wool fibers for possible cytotoxicity using alveolar macrophages, which are known to play a primary role in in vivo defense mechanisms against particles inhaled from outside of the body ${ }^{7}$, by applying our unique method of cell magnetometric evaluation. Since most chemical substances enter the body through the airway and are processed by alveolar macrophages, evaluation of the effects of these cells should be a useful system for screening the physiological effects of chemical 

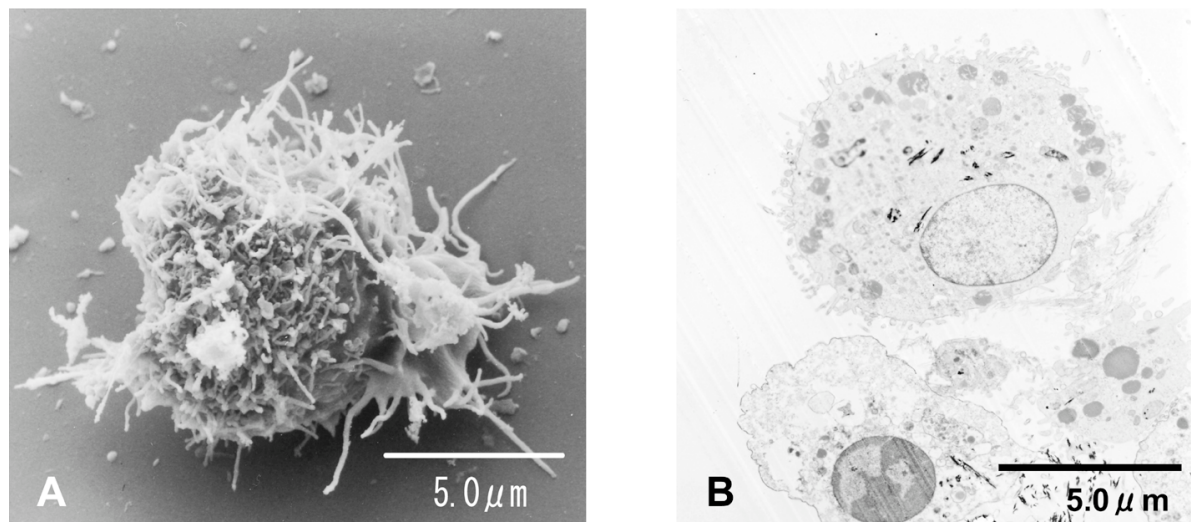

Fig. 7. (A) Electron micrograph of macrophages in the short CF-treated group (SEM). Macrophages appear to adhere to thin, small fibers with scarce presence of microvilli. (B) Electron micrograph of macrophages in the short CF-treated group (TEM). Vacuole formation in the cytoplasm is observed, with increased cells with a condensed nucleus.

substances. Furthermore, alveolar macrophages, due to their phagocytic activity, are suited for the evaluation of insoluble particles such as dust and fibrous substances like asbestos and asbestos substitutes. The harmful properties of the following chemical substances have been investigated by in vitro cell magnetometry: limestone (Keira et al., 1996) ${ }^{8}$, chrysotile (Keira et al., 1998) ${ }^{5}$, gallium arsenide (Okada et al., 1999) ${ }^{9}$, silicon carbide whiskers (Watanabe et al., 2000) ${ }^{10)}$, titanium dioxide (Watanabe et al., 2002) ${ }^{11}$, cadmium oxide (Niitsuya et al., 2003) $)^{12)}$, cadmium chloride (Cho, 2000) ${ }^{13)}$, arsenic chloride (Okada et al., 2001) ${ }^{14)}$, and photocopier toner

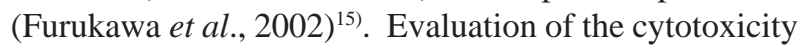
of silicon carbide whiskers by Watanabe et al. in 2000 ${ }^{10)}$ showed higher sensitivity of cell magnetometry in the detection of cytotoxicity, whereas no abnormalities were detected by the enzyme assay method. Similarly, Watanabe et al. reported that, in cell magnetometric evaluation, titanium dioxide in particle form did not cause cytotoxicity, but in a filamentous form caused cytotoxicity.

In in vivo studies on relaxation, Aizawa et al. reported in $1994^{16)}$ a delay after intratracheal instillation of gallium arsenide in rabbits. Möller et al. reported in $1996^{17)}$ a delay in smokers, and Fukushima et al. reported in $1995^{18)}$ facilitation of relaxation by influenza virus infection in rats.

Brain et al. argued in $1988^{19)}$, based on findings obtained in rats, that phagocytosis of iron oxide particles with time took place not as a result of exocytosis of the iron oxide particles but as a result of their rotation associated with translocation of intracellular organelles. Materials are incorporated in phagocytic vesicles after phagocytosis by macrophages, followed by their digestion. Intracytoplasmic translocation of these phagocytic vesicles and the cytoskeleton (mainly microtubles) is thought to play an important role in their polymerization and depolymerization. The cytoskeleton, which is mainly composed of microtubules, microfilaments and intermediate-diameter filaments, is known to play an important role in the maintenance of the cytoplasmic structure, intracellular transport and cellular polarity ${ }^{20-23)}$. It is thought that exposure to harmful substances causes delayed relaxation through their physical and chemical effects on the cytoskeleton ${ }^{4,1924)}$. Thus, delayed relaxation reflects a reduction of cytoskeletal function with rotation of phagosomes, and it is therefore considered to be an indicator of cytotoxicity. In cytotoxicity testing of silicon carbide whiskers, as noted above, no abnormality was observed when an enzymatic method for measurement of cell membrane permeability was used, but cellular damage was observed as delayed relaxation by cell magnetometry, showing its higher sensitivity in toxicity evaluation. Therefore, cell magnetometry appears to be valuable for the evaluation of cytotoxicity, in addition to conventional methods. The present study employed cell magnetometry, measurement of extracellularly leaked enzymes to evaluate damage to cellular membranes, DNA ladder detection to evaluate possible apoptosis as a process of cell death, and electronmicroscopic observation to evaluate morphological changes of subcellular structure. These methods enabled more comprehensive evaluation of cytotoxic effects on macrophages and could be useful for safety screening of chemical substances.

Cytotoxicity of fibers is considered to be determined by their chemical composition and physical properties (fiber size and fiber number). In the present study, relaxation was rapid in the HT wool-treated groups, 
whereas it was delayed in the CF-treated groups. In this study, cytotoxicity was higher with short CF than with long CF. This appeared to result from the fact that the number of short $\mathrm{CF}$ per unit weight was greater than that of long $\mathrm{CF}$, since the total surface area was larger with short $\mathrm{CF}$ at the same weight concentration. Furthermore, it has been reported that active oxygen is produced in macrophages by addition of asbestos. It is known that active oxygen, produced by alveolar macrophages, damages the lungs ${ }^{26)}$, and thus, lung damage by asbestos could possibly be caused by active oxygen produced by macrophages. Relaxation was delayed more in the CFtreated groups than in the HT wool-treated groups. Furthermore, HT wool is characterized by a higher dissolution rate at $\mathrm{pH} 4.5$ and a lower dissolution rate at $\mathrm{pH} 7.4$ than that of traditional types of $\mathrm{RW}^{27,28)}$. The $\mathrm{pH}$ of macrophage phagosomes is 4.5 . In other words, since HT wool was dissolved in phagosomes, its cytotoxicity in macrophages was lower than that of $\mathrm{CF}^{27,28)}$. The in vitro dissolution rate of silicon of HT wool was $59 \mathrm{ng} /$ $\mathrm{cm}^{2} / \mathrm{h}$ at $37^{\circ} \mathrm{C}$ in Gambles solution $(\mathrm{pH} 7.5)^{29)}$, while that of $\mathrm{CF}$ was $0.08 \mathrm{ng} / \mathrm{cm}^{2} / \mathrm{h}$ under the same conditions ${ }^{30)}$. This shows that the dissolution rate of HT wool is higher than that of $\mathrm{CF}$, and that the cytotoxicity of HT wool is lower than that of $\mathrm{CF}$.

In the present study, we measured LDH as a biochemical indicator. Measurement of LDH leaked from the cytoplasm of alveolar macrophages has been utilized as an indicator of cytotoxicity ${ }^{6}$. Our study results showed that the CF-treated groups had higher LDH activity than the PBS- and HT wool-treated groups. As mentioned above, since HT wool was dissolved in phagosomes, LDH release was lower in the HT wool-treated groups than in the CF-treated groups, suggesting HT wool fibers have lower cytotoxicity than $\mathrm{CF}^{27,28)}$.

DNA fragmentation, as determined by DNA ladder detection, is thought to be specific to apoptosis. In the present study, however, no fragmentation of DNA was observed in either the PBS- or HT wool-treated groups. On the other hand, Hamilton et al. ${ }^{31)}$ reported that chrysotile-exposed cells (human alveolar macrophages) showed formation of DNA ladders, which is characteristic of apoptosis, in 48-h cell cultures. The apparent difference between their results and those of our present study could be due to differences in the cell species and culture time.

Morphological examination by scanning microscopy and electronmicroscopy showed that cytotoxicity in macrophages was lower in the HT wool-treated groups than in the CF-treated groups. These results suggest that cytotoxicity after short-term exposure in vitro is less marked with HT wool fibers than with CF. We should further evaluate the safety of HT wool by lung magnetometry and morphological observation of the lung in in vivo inhalation studies.
Acknowledgement: We express thanks to Yumiko Sugiura, Yoko Inoue, Hiromi Komatsu and Michiyo Koyama of the Department of Preventive Medicine and Public Health at Kitasato University School of Medicine, as well as Shichiro Miyazawa and Noriko Nemoto of the Electron-microscopy Center. This work was supported by a Grant-in-Aid for Scientific Research from the Ministry of Health, Labour and Welfare, Japan in 2005.

\section{References}

1) Berry G. Mortality of workers certified by pneumoconiosis medical panels as having asbestosis. Br J Ind Med 1981; 38: 130-7.

2) Gormley IP, Bolton RE, Brown GM, Davis JM, Wright A. Some observations on the in vitro cytotoxicity of chrysotile prepared by the wet dispersion process. Environ Health Perspect 1983; 51: 35-9.

3) Koshi K, Sakabe H. Effect of asbestos dusts on the cultured macrophages. Ind Health 1972; 10: 16-23.

4) Cohen D. Ferromagnetic contamination in the lungs and other organs of the human body. Science 1973; 180: 745-8.

5) Keira T, Okada M, Katagiri H, Aizawa Y, Okayasu I, Kotani M. Magnetometric evaluation for the effect of chrysotile on alveolar macrophages. Tohoku J Exp Med 1998; 186: 87-98.

6) Wroblewski F, Ladue JS. Lactic dehydrogenase activity in blood. Proc Soc Exp Biol Med 1955; 90: 210-3.

7) Sibille Y, Reymonds HY. Macrophages and polymorphonuclear neutrophils in lung defense and injury. Am Rev Respir Dis 1990; 141: 471-501.

8) Keira T, Karube H, Aizawa Y, et al. Effect of limestone on the alveolar macrophages of hamsters. Jpn J Traumatol Occup Med 1996; 44: 313-8 (in Japanese).

9) Okada M, Karube H, Niitsuya M, Aizawa Y, Okayasu I, Kotani M. In vitro toxicity of gallium arsenide in alveolar macrophages evaluated by magnetometry, cytochemistry and morphology. Tohoku J Exp Med 1999; 189: 267-81.

10) Watanabe M, Okada M, Aizawa $Y$, Sakai Y, Yamashina S, Kotani M. Magnetic evaluation for the effects of silicon carbide whisker on alveolar macrophages. Ind Health 2000; 38: 239-45.

11) Watanabe M, Okada M, Kudo Y, et al. Differences in the effects of fibrous and particulate titanium dioxide on alveolar macrophages of Fischer 344 rats. J Toxicol Environ Health A 2002; 65: 1047-60.

12) Niitsuya $M$, Watanabe $M$, Okada $M$, et al. Magnetometric evaluation of cadmium oxide-induced toxicity to pulmonary alveolar macrophages of Syrian golden hamsters. J Toxicol Environ Health A 2003; 66: 365-78.

13) Cho YC. In vitro magnetometry, LDH activity and apoptosis as indices of cytotoxicity in alveolar macrophages exposed to cadmium chloride. Kor J Env Hlth Soc 2000; 26: 115-21.

14) Okada M, Inoue $Y$, Karube $H$, et al. Cytotoxic evaluation of arsenic compounds in alveolar macrophages in hamsters. Appl Organometal Chem 
2001; 15: 252-60.

15) Furukawa Y, Aizawa Y, Okada M, Watanabe M, Niitsuya M, Kotani M. Negative effect of photocopier toner on alveolar macrophages determined by in vitro magnetometric evaluation. Ind Health 2002; 40: 214 21.

16) Aizawa $Y$, Takata T, Karube H, Nakamura K, Kotani M. Effects of $\mathrm{GaAs}$ and $\mathrm{Ga}_{2} \mathrm{O}_{3}$ on magnetometric behavior of iron oxide particles in rabbit lungs. Appl Organometal Chem 1994; 8: 207-13.

17) Möller W, Barth W, Pohlit W, Rust M. Smoking impairs alveolar macrophage activation after inert dust exposure. Toxicol Lett 1996; 88: 131-7.

18) Fukushima T, Sekizawa K, Yamaya M, Okinaga $S$, Satoh M, Sasaki H. Viral respiratory infection increases alveolar macrophage cytoplasmic motility in rats: Role of NO. Am J Physiol 1995; 268: 399-406.

19) Brain JD, Bloom SB, Valberg PA. Magnetometry: A tool for studying the cell biology of macrophages. In: Atsumi K, Kotani M, Ueno S, Katila T, Williamson SJ, editors. Biomagnetism'87. Tokyo (Japan):Tokyo Denki University Press; 1988. p. 10-7 (in Japanese).

20) Malorni W, Iosi F, Falchi M, Donelli G. On the mechanism of cell internalization of chrysotile fibers: An immunocytochemical and ultrastructural study. Environ Res 1990; 52: 164-77.

21) Cassimeris L. Regulation of microtubule dynamic instability. Cell Motil Cytoskeleton 1993; 26: 275-81.

22) Maccioni RB, Combiazo V. Role of microtubuleassociated proteins in the control of microtubule assembly. Physiol Rev 1995; 75: 835-64.
23) Brinkley W. Microtubules: A brief historical perspective. J Struct Biol 1997; 118: 84-6.

24) Nemoto I, Ogura K, Toyotama H. Estimation of the energy of cytoplasmic movements by magnetometry: Effects of temperature and intracellular concentration of ATP. IEEE Trans Biomed Eng 1989; 36: 598-607.

25) Morgan A, Davis P, Wanger JC Berry G, Holmes A. The biological effects of magnesium-leached chrysotile asbestos. Brit J Exp Path 1977; 58: 465-73.

26) Donaldson K, Cullen RT. Chemiluminescence of asbestos-activated macrophages. Br J Exp Pathol 1984; 65: 81-90.

27) IARC Working Group on the Evaluation of Carcinogenic Risks to Humans. Man-made vitreous fibers. IARC Monogr Eval Carcinog Risks Hum 81. Lyon (France):IARC; 2002.

28) Kamstrup O, Ellehauge A, Chevalier J, Davis JM, McConnell EE, Thevenaz P. Chronic inhalation studies of two types of stone wool fibers in rats. Inhal Toxicol 2001; 13: 603-21.

29) Kamstrup O, Davis JM, Ellehauge A, Guldberg M. The biopersistence and pathology of man-made vitreous fibers after short- and long-term inhalation. Ann Occup Hyg 1998; 42: 191-9.

30) Law BD, Bunn WB, Hesterberg TW. Solubility of polymeric organic fibers and manmade vitreous fibers in Gambles solution. Inhal Toxicol 1990; 2: 321-39.

31) Hamilton RF, Iyer LL, Holian A. Asbestos induces apoptosis in human alveolar macrophages. Am J Physiol 1996; 271: 813-9. 